\title{
Simultaneous nitrification and formaldehyde biodegradation in an activated sludge unit
}

\author{
M. Eiroa, C. Kennes, M.C. Veiga \\ Bioresource Technologye, Volume 96, Issue 17, 2005, Pages 1914-18
}

DOI: 10.1016/j.biortech.2005.01.041

\begin{abstract}
The simultaneous removal of formaldehyde and ammonium in a lab-scale activated sludge unit was investigated. The unit was operated at a hydraulic retention time of 2.4

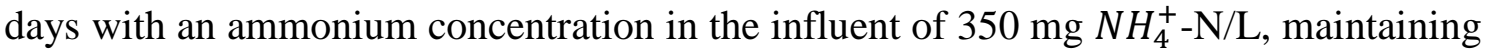
the ammonium loading rate at $0.15 \mathrm{~g} \mathrm{NH}+\mathrm{-N} / \mathrm{L}$ d during the operation time. However, the applied organic loading rate was increased stepwise by increasing the formaldehyde concentration from 26 up to $3168 \mathrm{mg} / \mathrm{L}$, corresponding to $0.01-1.40 \mathrm{~g} \mathrm{COD} / \mathrm{L} \mathrm{d}$. High formaldehyde removal efficiencies, around $99.5 \%( \pm 0.38)$, were maintained at all the formaldehyde concentrations. Ammonium removal was also very high during the operation period, around $99.9 \%( \pm 0.01)$. The ammonium concentration in the effluent was lower than $0.1 \mathrm{mg} \mathrm{NH}_{4}^{+}-\mathrm{N} / \mathrm{L}$ at all applied organic loading rates, indicating that there was no inhibition of nitrification by formaldehyde.
\end{abstract}

\section{Keywords}

Formaldehyde; Ammonium; Aerobic biodegradation; Nitrification; Activated sludge reactor.

\section{Introduction}

Synthetic resin producing industries generate wastewaters with high levels of nitrogen compounds (56-1462 mg TKN/L) and organic matter including formaldehyde as major component (7-2711 mg $\mathrm{CH}_{2} \mathrm{O} / \mathrm{L}$ ) (Cantó et al., 1998). The treatment of such wastewaters requires the simultaneous removal of nitrogen and organic compounds which can be done in an activated sludge reactor.

Biological nitrogen removal in wastewater treatment processes is carried out by microbial nitrification and denitrification. During the nitrification step, ammonium is oxidized to nitrate under aerobic conditions; and during the denitrification step, nitrate is reduced to molecular nitrogen in the presence of a carbon source under anoxic conditions. Nitrification is carried out in two steps, namely the conversion of ammonium to nitrite by ammonium oxidizers followed by the further conversion of nitrite to nitrate by nitrite oxidizers. Both types of bacteria are autotrophic organisms utilizing carbon dioxide as the carbon source for biosynthesis and oxidizing nitrogen compounds as the energy source. Nitrification is commonly the rate limiting step of the 
overall nitrogen removal. In the presence of toxic compounds, even at low concentrations, the nitrification process may be inhibited.

Formaldehyde is a common compound in the chemical industry, used in a large variety of processes and frequently found in wastewaters and waste gases causing environmental pollution (Prado et al., 2003). Due to its extreme reactivity, formaldehyde is regarded as a very toxic agent with severe negative action on living organisms. Because of its high toxicity, formaldehyde is often used as an active ingredient in preservatives and disinfectant agents to inhibit microbial activity. Therefore, its presence is expected to inhibit biological nitrogen removal in aerobic wastewater treatment plants. Nevertheless, formaldehyde is known to be biodegradable under aerobic conditions. Bonastre et al. (1986) reported the partial biodegradation of formaldehyde at concentrations of $2300 \mathrm{mg} / \mathrm{L}$ in tests with activated sludge. In another study, it was reported that Pseudomonas putida A2 degraded $400 \mathrm{mg} / \mathrm{L}$ formaldehyde as the sole carbon source in batch assays ( Adroer et al., 1990). Azachi et al. (1995) found that Halomonas sp. MA-C was able to degrade $100 \mathrm{mg} / \mathrm{L}$ formaldehyde in a salt medium. Yamazaki et al. (2001) studied the biodegradation of formaldehyde by a formaldehyde-resistant bacterium isolated from coastal seawater. Cells precultured in the presence of 200 or $400 \mathrm{mg} / \mathrm{L}$ formaldehyde were able to completely degrade $200 \mathrm{mg} / \mathrm{L}$ formaldehyde within $15 \mathrm{~h}$. Hidalgo et al. (2002) reported formaldehyde removal in a synthetic medium and industrial wastewater by Rhodococcus erythropolis UPV-1. At a rate of $0.41 \mathrm{mg} / \mathrm{L} \mathrm{h}$, the formaldehyde was completely removed over long periods of time.

The aim of the present work was to study the simultaneous removal of formaldehyde and ammonium in a lab-scale activated sludge unit. The biodegradability of formaldehyde and its effect on the nitrification process were investigated. Such information is useful for optimizing the treatment of wastewater that contains both formaldehyde and nitrogen compounds.

\section{Methods}

\subsection{Analytical methods}

Formaldehyde was determined spectrophotometrically according to the Hantzch reaction (Nash, 1953). A properly diluted formaldehyde solution was supplemented with acetyl acetone and ammonium acetate to form a colored compound. This compound was analyzed at $412 \mathrm{~nm}$ using a UV/Vis Lambda 11 spectrophotometer (Perkin Elmer, Germany). Nitrite and nitrate anions were analyzed by capillary electrophoresis using a ${ }^{3 \mathrm{D}} \mathrm{CE}$ system (Hewlett Packard, Germany) with a micro capillary tube of fused silica (Eiroa et al., 2004a). A sodium phosphate solution was employed as the electrolyte and UV detection was undertaken at a wavelength of $214 \mathrm{~nm}$ and $450 \mathrm{~nm}$ as reference. Ammonium concentrations were checked with a selective electrode. Chemical oxygen demand (COD), volatile suspended solids (VSS), dissolved oxygen (DO) and pH were evaluated according to Standard Methods ( APHA, 1998). 


\subsection{Experimental unit}

A lab-scale activated sludge reactor consisting of an aeration basin coupled to an external settler with a useful volume of $1.8 \mathrm{~L}$ was used (Fig. 1). In this unit, water to be treated was aerated and mixed with the sludge in the aeration basin. The treated water was separated from the sludge in the settler and the sludge was recycled in a temporized fashion to the aeration basin. Diffusers, located at the bottom of the aeration basin, supplied air from an air pump and maintained complete mixing.

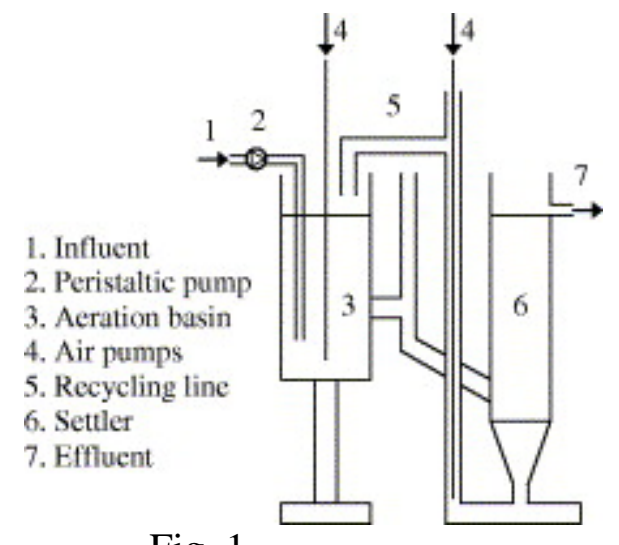

Fig. 1.

Scheme of the activated sludge unit.

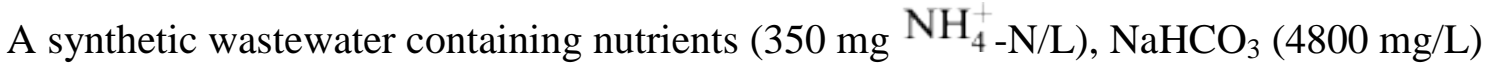
and formaldehyde was fed. The nutrients solution was composed of $(\mathrm{mg} / \mathrm{L})$ : $\mathrm{MgSO}_{4} \cdot 7 \mathrm{H}_{2} \mathrm{O}$ 84, $\mathrm{KH}_{2} \mathrm{PO}_{4}$ 175, $\left(\mathrm{NH}_{4}\right)_{2} \mathrm{SO}_{4}$ 826, $\mathrm{NaCl} 700, \mathrm{NH}_{4} \mathrm{Cl} 672$; and $0.05 \mathrm{~mL} / \mathrm{L}$ of the trace elements solution containing $(\mathrm{mg} / \mathrm{L}): \mathrm{CaCl}_{2} \cdot 2 \mathrm{H}_{2} \mathrm{O} 7350$, $\mathrm{MnCl}_{2} \cdot 4 \mathrm{H}_{2} \mathrm{O} 5060, \mathrm{FeSO}_{4} \cdot 7 \mathrm{H}_{2} \mathrm{O}$ 5000, $\left(\mathrm{NH}_{4}\right)_{6} \mathrm{Mo}_{7} \mathrm{O}_{24} \cdot 4 \mathrm{H}_{2} \mathrm{O}$ 1050, $\mathrm{Na}_{2}$ (AEDT) 50,000, $\mathrm{CuSO}_{4} \cdot 5 \mathrm{H}_{2} \mathrm{O} 1570, \mathrm{CoCl}_{2} \cdot 6 \mathrm{H}_{2} \mathrm{O} 1570$ and $\mathrm{ZnCl}_{2} 1040$.

\subsection{Experimental design and statistical analysis}

In order to investigate the simultaneous removal of formaldehyde and ammonium in an activated sludge unit, the ammonium loading rate was maintained constant during the experiment. The organic loading rate was increased stepwise by increasing the formaldehyde concentration. Each organic loading rate was maintained in the system during a period of time at least three times greater than the applied hydraulic retention time in order to reach steady-state conditions.

Formaldehyde, nitrite, nitrate, ammonium, COD, VSS, DO and $\mathrm{pH}$ were measured on a regular basis. All analyses were carried out in duplicate. Statistical analysis was performed using Excel for Windows XP. Removal percentages were expressed as the means ( \pm standard deviations).

\section{Results and discussion}

The reactor was initially inoculated with sludge obtained from the aerobic chamber of the full-scale wastewater treatment plant of a synthetic resin producing industry. The 
unit had been operating for 50 days before the present research was started. During that preliminary period the ammonium loading rate had been increased up to $0.15 \mathrm{~g} \mathrm{NH}_{4}^{+}$$\mathrm{N} / \mathrm{L} \mathrm{d}$. Afterwards, the unit worked at a hydraulic retention time of 2.4 days with an

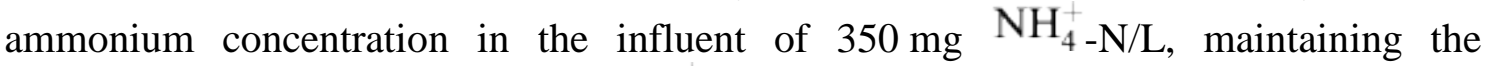

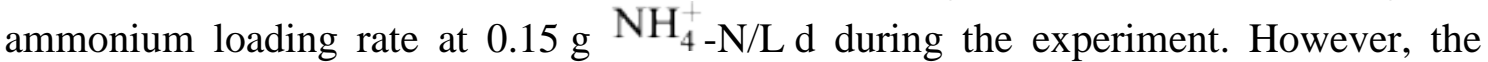
organic loading rate was increased stepwise by increasing the formaldehyde concentration from 26 up to $3168 \mathrm{mg} / \mathrm{L}(0.01-1.40 \mathrm{~g}$ COD/L d).

The $\mathrm{pH}$ level in the reactor fluctuated between 7.6 and 8.4, which is close to the optimum range for nitrifying bacteria (Antoniou et al., 1990). Dissolved oxygen in the reactor was maintained between $5.0 \mathrm{mg} / \mathrm{L}$ and $7.9 \mathrm{mg} / \mathrm{L}$ by aeration and temperature was around $20^{\circ} \mathrm{C}$. No biomass was purged from the reactor during the experimental period. The biomass concentration in the reactor increased from an initial value of $920 \mathrm{mg} \mathrm{VSS} / \mathrm{L}$ to $6560 \mathrm{mg} \mathrm{VSS} / \mathrm{L}$ after six months of operation. The biomass concentration in the effluent varied between 6 and $58 \mathrm{mg}$ VSS/L during the operation period. Sludge with good settling properties and a satisfactory effluent with low concentrations of suspended solids were obtained. The efficiency of settling of the activated sludge is mainly dependent on its ability to form flocs. High dissolved oxygen concentrations were maintained in the unit during the operation time and it is known that high values of dissolved oxygen produce flocs with high density and good settling properties (Wilén and Balmér, 1999).

\subsection{Biodegradation of formaldehyde}

In order to study the biodegradability of formaldehyde in the lab-scale activated sludge unit, the applied organic loading rate was increased from 0.01 up to $1.40 \mathrm{~g} \mathrm{COD/L} \mathrm{d.}$ The formaldehyde concentration in the influent and effluent of the unit is shown in Fig. 2. Although the formaldehyde concentration in the effluent remained always very low (less than $30 \mathrm{mg} / \mathrm{L}$ ), the increase of the formaldehyde concentration in the influent (26$3168 \mathrm{mg} / \mathrm{L}$ ) caused a slight increase of the formaldehyde concentration in the effluent. However, high formaldehyde removal efficiencies, around 99.5\% $( \pm 0.38)$, were maintained at all of the applied organic loading rates. The unit was stable throughout the six-month operation period and the removal of formaldehyde was highly efficient. These results indicate that the continuous aerobic treatment of wastewaters with high levels of formaldehyde, as in the case of wastewaters from synthetic resins producing factories, can efficiently be undertaken in an activated sludge reactor.

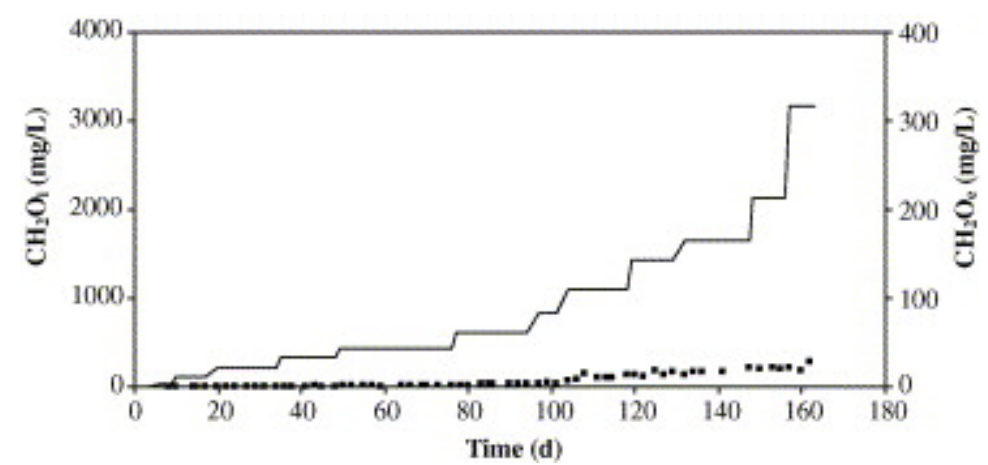

Fig. 2.

Formaldehyde concentration in the influent (-) and in the effluent ( $\mathbf{\square})$. 
The results observed are in agreement with data obtained from aerobic batch assays that were carried out with sludge obtained from the same industrial wastewater treatment plant (Eiroa et al., 2004a). In these batch assays, formaldehyde biodegradation was investigated at concentrations ranging from 30 to $3890 \mathrm{mg} / \mathrm{L}$. Complete formaldehyde biodegradation was observed in all cases. In continuous assays performed in our laboratory but in a denitrifying medium, formaldehyde was also completely biodegraded in the presence of urea (Eiroa et al., 2004b). Formaldehyde removal efficiencies above $99.5 \%$ were obtained in a lab-scale upflow sludge blanket reactor at organic loading rates between 0.37 and $2.96 \mathrm{~g} \mathrm{COD} / \mathrm{L} \mathrm{d}\left(625-5000 \mathrm{mg} \mathrm{CH}_{2} \mathrm{O} / \mathrm{L}\right.$ ). In other continuous assays performed in a denitrifying medium but in the presence of phenol, formaldehyde was also completely biodegraded (Eiroa et al., 2005). Formaldehyde removal efficiencies above $99.5 \%$ were obtained at all the applied formaldehyde loading rates, between 0.14 and $0.89 \mathrm{~g}$ COD/L $\mathrm{d}$.

The formaldehyde concentration in the influent was easily degraded in the activated sludge unit. However, about $18 \%( \pm 2.15)$ of the influent COD was present in the effluent of the unit, indicating the possible existence of products of degradation. Some of the remaining COD in the effluent might also be due to extra enzymes or inert bio products released from the sludge in the reactor caused by turbulent shear stress (Cheng and Chen, 1994). The possible products of formaldehyde biodegradation are methanol and formic acid since batch assays performed in our laboratory with the same sludge proved that formaldehyde was transformed into methanol and formic acid. In these assays, the initial amount of formaldehyde ranged between 160 and $1360 \mathrm{mg} / \mathrm{L}$. This compound was completely biodegraded in all cases in few days. But the formaldehyde biodegradation led to the simultaneous appearance of methanol and formic acid. The degradation of methanol and formic acid began after exhaustion of formaldehyde in the medium. This is in agreement with results obtained by Kato et al. (1983) studying aerobic formaldehyde biodegradation by Pseudomonas putida F61. They found an enzyme, which catalyzed dismutation of formaldehyde to form methanol and formic acid. Adroer et al. (1990) studied the mechanism of aerobic formaldehyde biodegradation by a strain of Pseudomonas putida. Their results indicated that the biodegradation led to the simultaneous appearance of methanol and formic acid. The degradation of methanol and formic acid began after exhaustion of formaldehyde in the medium.

\subsection{Nitrification in presence of formaldehyde}

Ammonium removal in the presence of formaldehyde was also investigated in the activated sludge reactor. The effect of the organic loading on nitrogen removal is an important issue to be evaluated because organic matter and nitrogen removal are often carried out within the same reactor. As mentioned above, before this research the unit was operated at an ammonium loading rate of $0.15 \mathrm{~g} \mathrm{NH}+\mathrm{N} / \mathrm{L} \mathrm{d}$, obtaining ammonium removals of $99.9 \%( \pm 0.01)$. Afterwards, in order to study the effect of formaldehyde on nitrogen removal, the ammonium loading rate was maintained constant and the organic loading rate was increased up to $1.40 \mathrm{~g} \mathrm{COD/L} \mathrm{d} \mathrm{(Fig.} \mathrm{3).} \mathrm{The} \mathrm{evolution} \mathrm{of} \mathrm{the}$ concentration of nitrogen compounds in the influent and effluent of the unit is shown in Fig. 4. Nitrite concentration was omitted because this compound was not detected at any formaldehyde concentration. Ammonium removal was very high during the operation period, around $99.9 \%( \pm 0.01)$. The ammonium concentration in the effluent was lower 
than $0.1 \mathrm{mg} \mathrm{NH}_{4}^{+} \mathrm{NH} 4+-\mathrm{N} / \mathrm{L}$ at all applied organic loading rates, indicating that there was no inhibition of nitrification by formaldehyde.

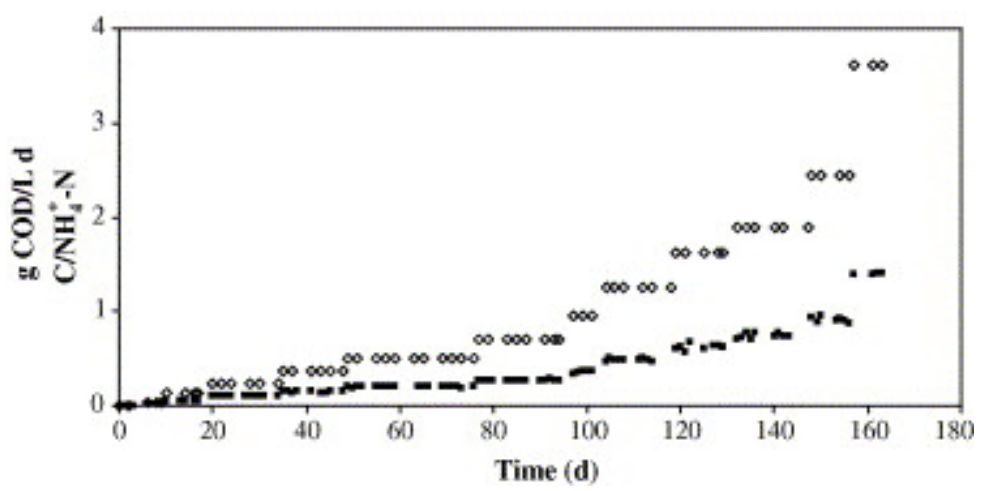

Fig. 3.

Evolution of the applied organic loading rate $(\boldsymbol{\bullet})$ and $\mathrm{C} / \mathrm{NH}_{4}^{+}-\mathrm{N}$ ratio $(\diamond)$.

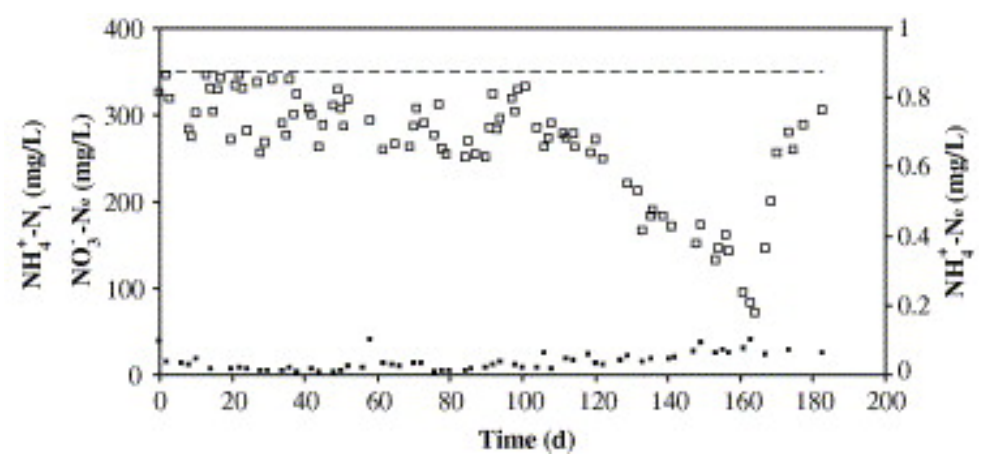

Fig. 4.

Evolution of the nitrogen compounds concentration: ammonium in the influent $(--)$ and effluent ( $\square)$, and nitrate in the effluent $(\square)$.

Regarding the nitrification percentage, values between $72 \%$ and $99 \%$ (about $85 \%$ $( \pm 8.12)$ ) were reached up to a formaldehyde loading rate of $0.48 \mathrm{~g} \mathrm{COD} / \mathrm{L} \mathrm{d}$. Afterwards, the nitrate concentration in the effluent decreased, which does not mean that there were inhibitory effects of formaldehyde because the ammonium concentration in the effluent was always near to zero. This decrease can be basically attributed to denitrification and to small range ammonium assimilation by the heterotrophs.

Denitrification in the aerobic unit could occur because of anaerobic micro zones in the centre of the sludge flocs. Organic matter served as the electron donor. The decrease in the nitrification percentage was observed since the $\mathrm{C} / \mathrm{NH}_{4}^{+}-\mathrm{N}$ ratio in the influent was increased to 1.6 (Fig. 3). The increase in the $\mathrm{C} / \mathrm{NH}_{4}^{+}-\mathrm{N}$ ratio could enhance denitrification. In order to explain this decrease in the nitrate concentration by denitrification, the addition of formaldehyde to the influent was stopped on day 164. As a result, the nitrification percentage increased from this day. Hence simultaneous nitrification and denitrification took place in the unit.

Another possible mechanism explaining part of the decrease in the nitrate concentration in the effluent can be ammonium assimilation by the heterotrophs. Assimilation of 
ammonium by the nitrifiers is small; however, it becomes significant when the heterotrophs grow with organic matter (Akunna et al., 1994 and Rostron et al., 2001). The biomass in the reactor increased substantially and the assimilation of ammonium by the heterotrophs was faster than nitrification. Only excess ammonium was utilized by the nitrifiers for nitrification (Hanaki et al., 1990 and Cheng and Chen, 1994). Therefore, ammonium assimilation by the heterotrophs reduced the amount of ammonium available to the nitrifiers, and decreased the achievable nitrification percentage. Higher organic loading rates resulted in more ammonium assimilation by the heterotrophs.

In the present research, inhibition of ammonium removal by formaldehyde was not observed even at high organic loading rates, because of the fast, complete biodegradation of that carbon source by heterotrophs. Therefore, the continuous aerobic treatment of wastewaters with high levels of formaldehyde and ammonium can efficiently be undertaken in an activated sludge reactor. These data are different than the results obtained in aerobic batch assays that were carried out with sludge obtained from the same industrial wastewater treatment plant (Eiroa et al., 2004a). In these batch assays, the addition of formaldehyde was inhibitory for the nitrification process, showing higher inhibition levels when increasing the initial formaldehyde concentration. At initial formaldehyde concentrations lower than $1500 \mathrm{mg} / \mathrm{L}$, nitrite production was observed in a first stage and later nitrite was transformed into nitrate. However, nitrification was completely inhibited at initial formaldehyde concentrations above $1500 \mathrm{mg} / \mathrm{L}$. This discrepancy between continuous and batch assays can be explained because the formaldehyde concentration in the continuous reactor was always very low (less than $30 \mathrm{mg} / \mathrm{L}$ ).

\section{Conclusions}

High formaldehyde removal efficiencies, around $99.5 \%( \pm 0.38)$, were maintained at all the applied organic loading rates $(0.01-1.40 \mathrm{~g}$ COD/L d). The unit was stable during the entire experiment. The applied ammonium loading rate was maintained at $0.15 \mathrm{~g} \mathrm{NH} \mathrm{N}_{4}^{+}$ $\mathrm{N} / \mathrm{L} \mathrm{d}$ and ammonium removal was also very high, around 99.9\% $( \pm 0.01)$. The

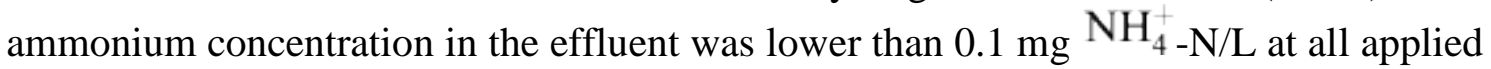
organic loading rates, indicating that there was no inhibition of nitrification by formaldehyde.

Present results indicate that the continuous aerobic treatment of wastewaters with high levels of formaldehyde and ammonium can efficiently be undertaken in an activated sludge reactor.

\section{Acknowledgement}

The present research has been funded by the Spanish Ministry of Science and Technology CICYT (projects REN2000-0218-P4-02 and PPQ 2002-02882) and by the Xunta de Galicia (project PGIDIT03PXIC10304PN). M. Eiroa is grateful to the Spanish Ministry of Education and Culture for a fellowship. 


\section{References}

N. Adroer, C. Casas, C. de Mas, C. Solà

Mechanism of formaldehyde biodegradation by Pseudomonas putida

Appl. Microbiol. Biotechnol., 33 (1990), pp. 217-220

J. Akunna, C. Bizeau, R. Moletta, N. Bernet, A. Heduit

Combined organic carbon and complete nitrogen removal using anaerobic and aerobic upflow filters

Wat. Sci. Tech., 30 (12) (1994), pp. 297-306

P. Antoniou, J. Hamilton, B. Koopman, R. Jain, B. Holloway, G. Lyberatos, S.A. Svoronos

Effect of temperature and $\mathrm{pH}$ on the effective maximum specific growth rate of nitrifying bacteria

Wat. Res., 24 (1) (1990), pp. 97-101

APHA, 1998. Standard Methods for the Examination of Water and Wastewater. 20th ed., Washington DC, USA.

M. Azachi, Y. Henis, A. Oren, P. Gurevich, S. Sarig

Transformation of formaldehyde by a Halomonas sp

Can. J. Microbiol., 41 (1995), pp. 548-553

N. Bonastre, C. de Mas, C. Solà

Vavilin equation in kinetic modelling of formaldehyde biodegradation

Biotechnol. Bioeng., 28 (1986), pp. 616-619

Cantó, M., Gómez, J., Kennes, C., Veiga, M.C., 1998. Integrated anoxic-aerobic treatment of wastewaters from a synthetic resin producing factory. European Conference on New Advances in Biological Nitrogen and Phosphorus Removal for Municipal or Industrial Wastewaters, Narbonne, France.

S. Cheng, W. Chen

Organic carbon supplement influencing performance of biological nitritification in a fluidized bed reactor

Wat. Sci. Tech., 30 (11) (1994), pp. 131-142

M. Eiroa, C. Kennes, M.C. Veiga

Formaldehyde biodegradation and its inhibitory effect on nitrification

J. Chem. Technol. Biotechnol., 79 (2004), pp. 499-504

M. Eiroa, C. Kennes, M.C. Veiga

Formaldehyde and urea removal in a denitrifying granular sludge blanket reactor

Water Res., 38 (2004), pp. 3495-3502

M. Eiroa, A. Vilar, L. Amor, C. Kennes, M.C. Veiga

Biodegradation and effect of formaldehyde and phenol on the denitrification process

Water Res., 39 (2005), pp. 449-455 
K. Hanaki, C. Wantawin, S. Ohgaki

Effects of the activity of heterotrophs on nitrification in a suspended-growth reactor

Wat. Res., 24 (3) (1990), pp. 289-296

A. Hidalgo, A. Lopategi, M. Prieto, J.L. Serra, M.J. Llama

Formaldehyde removal in synthetic and industrial wastewater by Rhodococcus erythropolis UPV-1

Appl. Microbiol. Biotechnol., 58 (2002), pp. 260-263

N. Kato, K. Shirakawa, H. Kobayashi, C. Sakazawa

The dismutation of aldehydes by a bacterial enzyme

Agri. Biol. Chem., 47 (1) (1983), pp. 39-46

The colorimetric estimation of formaldehyde by means of the Hantzch reaction

Biochem. J., 55 (1953), pp. 416-421

Ó.J. Prado, M. Eiroa, M.C. Veiga, C. Kennes

Bioreactors for the treatment of industrial waste gases containing formaldehyde and other aliphatic compounds

S.N. Agathos, W. Reineke (Eds.), Focus on Biotechnology, Biotechnology for the Environment: Wastewater Treatment and Modelling, Waste Gas Handling, vol. 3CKluwer Academic Publishers, Dordrecht, The Netherlands (2003), pp. 259-273

W.M. Rostron, D.C. Stuckey, A.A. Young

Nitrification of high strength ammonia wastewaters: comparative study of immobilisation media

Wat. Res., 35 (5) (2001), pp. 1169-1178

B. Wilén, P. Balmér

The effect of dissolved oxygen concentration on the structure, size and size distribution of activated sludge flocs

Wat. Res., 33 (2) (1999), pp. 391-400

T. Yamazaki, W. Tsugawa, K. Sode

Biodegradation of formaldehyde by a formaldehyde-resistant bacterium isolated from seawater

Appl. Biochem. Biotechnol., 91-93 (2001), pp. 213-217 